\title{
Acebrophylline: an airway mucoregulator and anti-inflammatory agent
}

\author{
E. Pozzi
}

ABSTRACT: Acebrophylline: an airway mucoregulator and anti-inflammatory agent. E. Pozzi.

Acebrophylline is an airway mucus regulator with antiinflammatory action. The drug's approach involves several points of attack in obstructive airway disease. The molecule contains ambroxol, which facilitates various steps in the biosynthesis of pulmonary surfactant, theophylline-7 acetic acid whose carrier function raises blood levels of ambroxol, thus rapidly and intensely stimulating surfactant production. The resulting reduction in the viscosity and adhesivity of the mucus greatly improves ciliary clearance. By deviating phosphatidylcholine towards surfactant synthe- sis, making it no longer available for the synthesis of inflammatory mediators such as the leukotrienes, acebrophylline also exerts an inflammatory effect. This is confirmed in vivo by the reduction in aspecific bronchial hyperresponsiveness in patients with stable bronchial asthma.

On a clinical level, acebrophylline is therapeutically effective in patients with acute or chronic bronchitis, chronic obstructive or asthma-like bronchitis and recurrence of chronic bronchitis; it reduces the frequency of episodes of bronchial obstruction and reduces the need for $\beta_{2}$-agonists, and improves indexes of ventilatory function. Monaldi Arch Chest Dis 2007; 67: 2, 106-115.

Keywords: Acebrophylline, ambroxol, alveolar surfactant, airway hyper-responsiveness, chronic bronchitis, asthma-like bronchitis.

Pulmonary Diseases Department, IRCCS San Matteo, University of Pavia, Italy.

Correspondence: Ernesto Pozzi, Pulmonary Diseases Department, IRCCS San Matteo, Via Taramelli 5, 27100 Pavia, Italy; e-mail: ernesto.pozzi@unipv.it

\section{Introduction}

International preclinical and clinical literature acknowledges that airway mucus stasis and lack of surfactant are bound in a reciprocal causal relationship: by stimulating phospholipid synthesis one can act on the mucus stasis [1,2]. The phospholipids also serve as precursors for inflammatory mediators in the etiopathogenesis and maintenance of the chronic processes underlying chronic obstructive lung disease (COLD). There is a metabolic pathway common to pulmonary surfactant and to the leukotrienes LTB4, $\mathrm{LTC}_{4}, \mathrm{LTD}_{4}$ and $\mathrm{LTE}_{4}[3,4]$; it is therefore logical to assume that a drug such as acebrophylline, which partially inhibits phospholipase A [5], should not only influence the rheological properties of the mucus, facilitating its removal from the airways, but should also have "anti-inflammatory/antireactive" action, driving synthesis towards metabolites such as surfactant, with a physiological action in the patient rather than those with negative effects, like the leukotrienes [6].

A qualitative or quantitative lack of surfactant can in fact play a pathogenic role in bronchospasm, as reported by Enhorning et al. [7] and is confirmed by:

- epidemiological studies that report a higher incidence of bronchial asthma developing in premature babies, with their obvious lack of surfactant [8];

- the description of interactions between surfac- tant phospholipids and the bronchial irritative receptors that cause bronchial hyper-responsiveness, hence cough and bronchospasm, in many respiratory diseases. These receptors may be activated when not protected by an adequate lining of phospholipids [9];

- the recognition that factors triggering attacks of asthma have an effect on alveolar surfactant [10];

- the demonstration that drugs used to treat bronchospasm can induce the synthesis and release of alveolar lining [11];

- the fact that phospholipids in expectorate and bronchoalveolar lavage (BAL) from asthma patients differ in quality and quantity from those of healthy controls [12];

- the observation that inhalation of natural pulmonary surfactant by asthma patients during an acute attack significantly improves their respiratory function and the partial pressure of oxygen compared to patients given placebo [13].

It can therefore be concluded that drugs stimulating surfactant production have anti-reactive/antibronchospastic action. These include the corticosteroids [14], $\beta_{2}$-mimetic agents such as salbutamol and terbutaline [15], and xanthine derivatives [16]. Nevertheless, these drugs, however effective, must be used with caution and their risk/benefit ratio must always be assessed, on account of their potential for adverse reactions and interactions with other drugs [17-19]. 
Pharmacological research has focused on finding easier-to-handle molecules with dual action: bronchosecretolytic on the one hand, and stimulating the synthesis and release of pulmonary surfactant on the other, with ambroxol heading this last group [20].

Against this backdrop the compound acebrophylline has been developed and clinically tested; this is a natural pharmacological step forward from ambroxol, stimulating the production of pulmonary surfactant more promptly and strongly and ideal for use in children and adults. Not only does it improve the rheology of bronchial mucus and its transport, but it also controls bronchial hyperresponsiveness more directly, through a multifactorial approach.

\section{Chemical/physical properties of acebrophylline}

Acebrophylline is obtained by targeted salification of the ambroxol base [trans-4(2-amino-3,5 dibromobenzylamino) cyclohexanol] and theophylline 7 acetic acid. The carboxyl group of theophylline 7 acetic acid was salified with ambroxol's amine group in a stoichiometric ratio $(38.7 \%$ acid and $61.3 \%$ base) that ensures, after absorption, high plasma levels of ambroxol with low levels of the xanthine derivative which are nevertheless high enough to ensure a carrier effect for ambroxol [21]. This means that one hour after administration lung levels of ambroxol are 45\% higher than in subjects treated with ambroxol alone.

\section{Mechanism of action}

Studies have looked at the combined action of the two components of acebrophylline on the production of pulmonary surfactant and the benefits with regard to mucus regulation and mucokinetics, and the anti-inflammatory-antireactive action essential for clearing bronchial obstruction.

\section{1) Synthesis and release of pulmonary surfactant}

Surfactant production in the rat was compared, in terms of levels of total phospholipids and phosphatidylcholine in BAL after five days' treatment with acebrophylline, and in an untreated control group. An increase in the surfactant phospholipid matrix was evident just two hours after the last dose, and the rise was significantly greater in the treated group $(161 \pm 11 \mathrm{mcg} / \mathrm{mL})$ than in controls $(139 \pm 3.6 \mathrm{mcg} / \mathrm{mL})$ about 18 hours after the last dose [22] (fig. 1).

In order to assess the mechanism by which acebrophylline stimulates pulmonary surfactant synthesis and release, the drug's effect was investigated on the uptake of labeled surfactant precursors in rat lung slices, in order to see how much the tissue was stimulated to produce surfactant [22]. The uptake of ${ }^{14} \mathrm{C}$-choline, one of the precursors of phosphatidylcholine was compared with that of 32P-phosphate, a phospholipid precursor, in rats treated for five days with acebrophylline, or its components singly: ambroxol and theophylline 7 acetic acid. Compared to controls ${ }^{14} \mathrm{C}$-choline uptake in phosphatidylcholine was significantly higher after acebrophylline and ambroxol; theophylline 7 acetic acid also tended to increase uptake but not significantly. With ${ }^{32} \mathrm{P}$-phosphate acebrophylline increased uptake significantly more than controls, which had the same effect as ambroxol; again, theophylline-7 acetic acid tended to increase uptake, but not significantly (fig. 2).

The fact that acebrophylline induced the uptake not only of labeled choline but also of $32 \mathrm{P}$ phosphate suggests it acts on two levels on surfactant synthesis: the first involves ambroxol's estab-

\begin{tabular}{|c|c|c|c|}
\hline & & \multicolumn{2}{|c|}{$\begin{array}{l}2 \text { hours after the last dose } \\
\text { Bronchoalveolar lavage fluid }\end{array}$} \\
\hline Treatments & $\begin{array}{l}\text { Dose } \\
(\mathrm{mg} / \mathrm{kg})\end{array}$ & $\begin{array}{l}\text { Phospholipids tot } \\
\text { (mcg/ml) }\end{array}$ & $\begin{array}{l}\text { Phosphatidylcholine } \\
\text { (mcg/ml) }\end{array}$ \\
\hline Controls & - & $136 \pm 5$ & $102 \pm 4.6$ \\
\hline \multirow[t]{2}{*}{ Acebrophylline } & 160 & $159 \pm 10$ & $115 \pm 5.2$ \\
\hline & & \multicolumn{2}{|c|}{$\begin{array}{l}18 \text { hours after the last dose } \\
\text { Bronchoalveolar lavage fluid }\end{array}$} \\
\hline Treatments & $\begin{array}{c}\text { Dose } \\
(\mathrm{mg} / \mathrm{kg})\end{array}$ & $\begin{array}{l}\text { Phospholipids tot } \\
\text { (mcg/ml) }\end{array}$ & $\begin{array}{l}\text { Phosphatidylcholine } \\
\text { (mcg/ml) }\end{array}$ \\
\hline Controls & - & $195 \pm 18$ & $139 \pm 3.6$ \\
\hline Acebrophylline & 160 & $251 \pm 17$ & $161 \pm 11$ \\
\hline
\end{tabular}




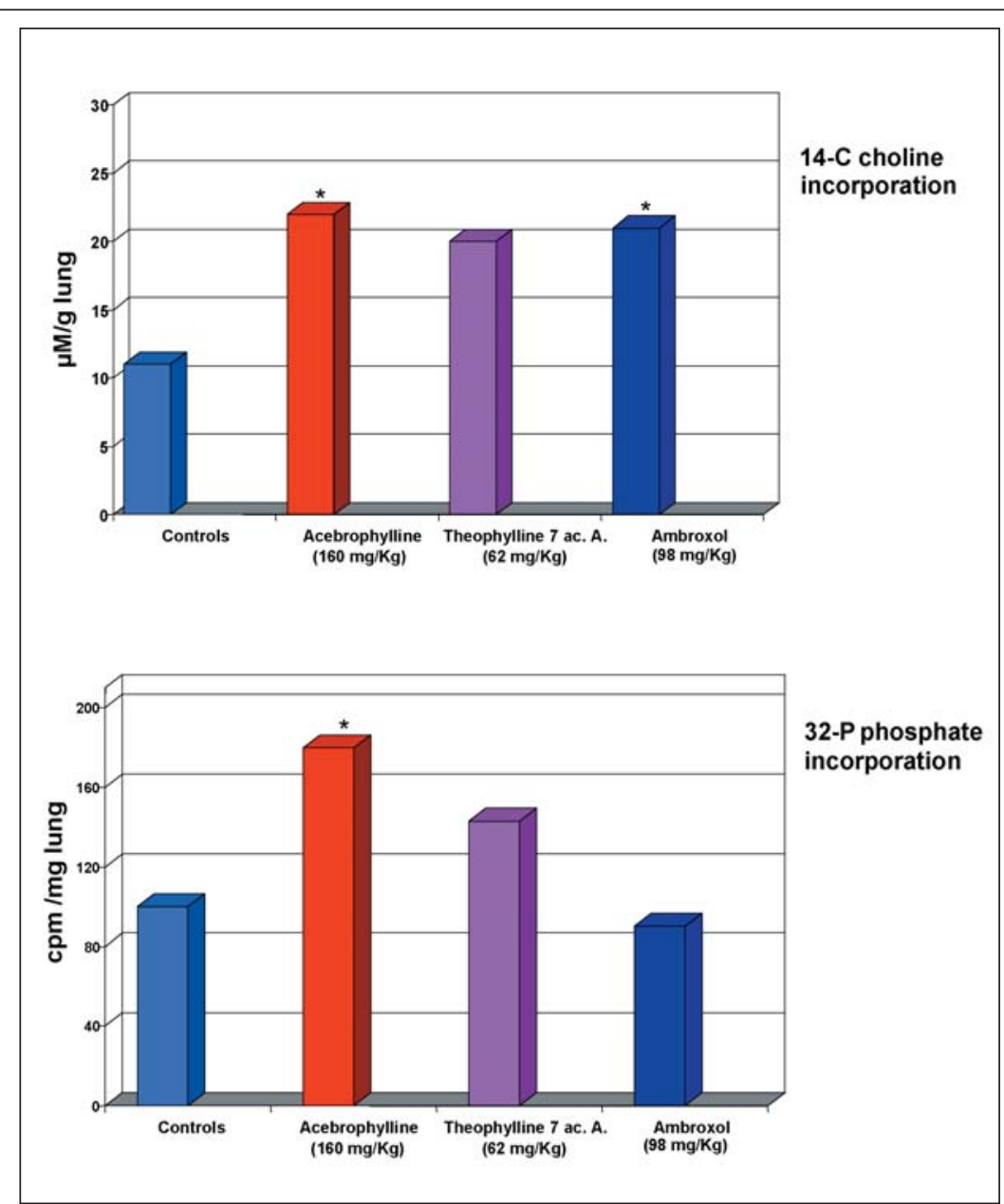

Fig. 2. - Effect of acebrophylline and its single components on the uptake of labeled phospholipid precursors in rat BAL. (Modified from F Scaglione, GIMT (Suppl 1); 1992: 67-72)

mucus production by the serous glands may be activated. Acebrophylline thus promotes the production of "better quality" secretion.

Indirect activity: by stimulating the production of alveolar surfactant the viscosity of bronchial secretions is reduced. As regards a possible physico-chemical interaction between mucus and phospholipids [31], bronchial phospholipids appear to have a part in the formation of the fibrillary structure of mucus. To form the supracilliary colloidal "gel" secreted mucus must pass through two layers: the so-called "sol" and the layer of phospholipids or inter-sol-gel; this implies a physico-chemical interaction between the mucus and the surfactant molecules. This interaction can induce the formation of emulsified particles of mucus, with lower microviscosity.

\section{3) Mucosecretory activity}

In the rabbit and mouse, the acebrophylline's activity on mucus was investigated by measuring the volume of bronchial secretion collected from the incannulated trachea, or by measuring the amount of phenol red secreted by the bronchial mucosa. In the tests with the dye, acebrophylline was more

lished action on phosphocholine-cytidyl-transferase $[25,26]$ and the second probably because of theophylline-7 acetic acid's action on choline-kinase [22] (fig. 3).

In cultured type II pneumocytes from rabbit BAL exposed to acebrophylline or equivalent doses of ambroxol, specific histochemical examination techniques [27] detected a definite increase in surfactant synthesis, particularly in the cells exposed to acebrophylline [23].

\section{2) Mucoregulating action}

Acebrophylline has dual action on pathological secretions: it acts directly as a mucoregulator, and indirectly by stimulating surfactant synthesis.

Direct activity: investigations in animals have shown that ambroxol, as an ingredient of acebrophylline, can restore the normal viscosity of abnormal bronchial secretion [28]. This is not through any direct action on mucus already secreted $[29,30]$ but through its ability to "regulate" and "balance" bronchial secretions at the glandular level. After treatment with this compound, in fact, mucosal cysts may regress to normal glandular acini and active than ambroxol alone, as confirmed by the amount secreted in relation to the $50 \%$ effective dose $\left(\mathrm{ED}_{50}\right)$ needed to reach much the same result, which was considerably lower for acebrophylline (0.278 $\mathrm{mM} / \mathrm{kg}$ p.o.) than ambroxol $(0.498 \mathrm{mM} / \mathrm{kg})$ [32].

\section{4) Activity on mucociliary clearance (mucokinet- ic activity)}

Acebrophylline's mucokinetic activity was confirmed by investigating its ability to increase the transport of talc particles in a given time in the isolated rabbit trachea, and to increase the amount 
of labeled fluorescein secreted and shifted into the trachea by the ciliary beats [32]. It is therefore quite possible that the stimulation of pulmonary surfactant by acebrophylline facilitates non-ciliary clearance as well, as the increase in surfactant eases transport of the secretions through the parts of the respiratory tract that have no cilia too [2]. The reduction in mucus adhesivity to the bronchial walls and its tendency to form smaller clumps when there is more surfactant certainly helps [2]. The expectorate from patients treated with acebrophylline has lower surface tension [32].

\section{5) Antiinflammatory-antireactive activity}

We have already mentioned that pulmonary surfactant and inflammatory mediators share phos-

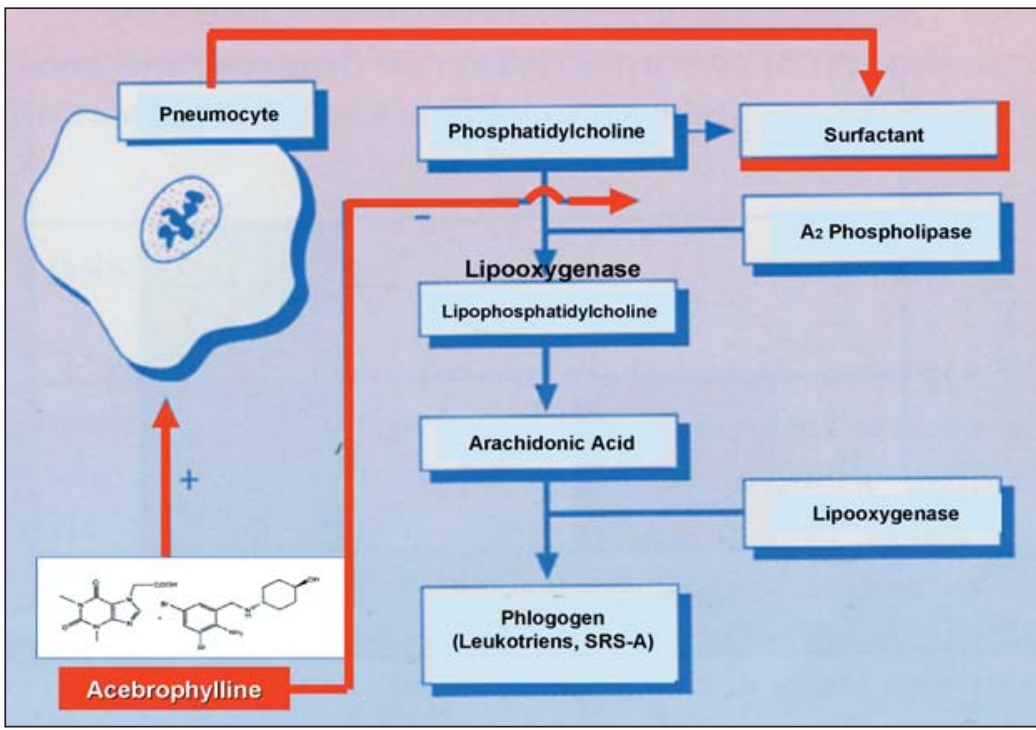

Fig. 4. - Effects on mucus and antiinflammatory action of acebrophylline.

(Modified from G Cocco, GIMT (Suppl 1); 1992: 103-107) phatidylcholine as their substrate. As acebrophylline partially inhibits phospholipase A [5] it can also inhibit the metabolisation of phosphatidylcholine. In the bronchi this means less formation of the leukotrienes that cause inflammation and bronchoreactions. This was confirmed by the finding that in human mononuclear cells ambroxol, one of the components of acebrophylline, reduced the production of tumour necrosis factor (TNF), an inflammatory mediator, and the airway hyperresponsiveness induced by ozone in vivo in the dog $[33,34]$.

In the parenchyma the blockade of phospholipase A leaves a reserve of phosphatidylcholine that type II pneumocytes can use to re-synthesise surfactant (fig. 4). Scaglione et al. [4], using cultured human type II pneumocytes, studied the action of acebrophylline and its single components; they confirmed that only acebrophylline significantly reduced the production of $\mathrm{LTB}_{4}$ leukotrienes, in favor of the surfactant constituents (table 1). Similarly, in vivo in rats pretreated with acebrophylline, and submitted to bronchial lavage at different times, leukotrienes $\mathrm{LTC}_{4}$ and $\mathrm{LTB}_{4}$ were reduced. The reduction in $\mathrm{LTB}_{4}$ was particularly significant compared to untreated controls, further confirming acebrophylline's antiinflammatory potential [4] (table 2).

By inhibiting the synthesis and release of inflammatory mediators, acebrophylline helps reduce bronchial edema secondary to inflammation, a key factor in airway obstruction, especially in chronic forms. The drug also has bronchodilating action, probably result-

Table 1. - Effect of acebrophylline in vitro $\left(10^{-4} \mathrm{mM}\right)$ on the production of leukotrienes and phospholipids in pulmonary surfactant

\begin{tabular}{lccc}
\hline Treatment & $\mathbf{L T C}_{\mathbf{4}}(\boldsymbol{\%})^{\Delta}$ & $\mathbf{L T B}_{\mathbf{4}}(\boldsymbol{\%}) \boldsymbol{\Delta}$ & $\begin{array}{c}\text { Total phospholipids } \\
\text { (ng/107 cells) }\end{array}$ \\
\hline Control & $100 \pm 1$ & $100 \pm 27$ & $708 \pm 17$ \\
Acebrophylline & $95 \pm 5$ & $53 \pm 5^{* *}$ & $916 \pm 21^{* *}$ \\
\hline
\end{tabular}

$\Delta$ Percentage of controls (mean of three replicates); Cultured A549 cells; $* * p \leq 0.01$ acebrophylline $v s$. controls.

Table 2. - Leukotrienes in BAL from rats treated with acebrophylline

\begin{tabular}{|c|c|c|c|c|}
\hline \multirow[t]{3}{*}{ Treatment } & \multicolumn{4}{|c|}{ Leukotrienes $\Delta$} \\
\hline & \multicolumn{2}{|c|}{ at $2 \mathrm{~h}$} & \multicolumn{2}{|c|}{ at $18 \mathrm{~h}$} \\
\hline & $\mathbf{L T B}_{4}$ & $\mathrm{LTC}_{4}$ & $\mathbf{L T B}_{4}$ & LTC $_{4}$ \\
\hline Control & $100 \pm 30$ & $100 \pm 9$ & $100 \pm 13$ & $100 \pm 21$ \\
\hline Acebrophylline & $51 \pm 3.5^{* *}$ & $69 \pm 3$ & $71 \pm 27$ & $80 \pm 14$ \\
\hline
\end{tabular}

$\Delta$ Percentage of controls (mean of three replicates); $* * p \leq 0.01$ acebrophylline $v s$. controls. 
ing from its anti-inflammatory effect (with a consequent reduction in bronchial responsiveness).

These pharmacological activities constitute the basis for a correct therapeutic approach to acute and chronic obstructive airway diseases.

\section{Pharmacokinetics}

In healthy volunteers, given $200 \mathrm{mg}$ oral acebrophylline, the two components of the molecule ambroxol and theophylline-7 acetic acid are released in the stomach and absorbed there and in the intestine, reaching optimal concentrations of ambroxol and very low levels of theophylline-7 acetic acid. Ambroxol reaches its peak in serum (mean $\mathrm{C}_{\max } 0.369 \mathrm{mcg} / \mathrm{mL}$ ) at $2 \mathrm{hrs}$ and theophylline-7 acetic acid after $1 \mathrm{hr}$ (mean $\mathrm{C}_{\max } 0.008$ $\mathrm{mcg} / \mathrm{mL}$ ). Thus it appears that the latter is either poorly absorbed or metabolised very fast and is eliminated in a fairly short time. Its low blood levels mean it is not likely to cause the untoward effects seen in man after theophylline, whose therapeutic window corresponds to much higher plasma concentrations $(10-20 \mathrm{mcg} / \mathrm{mL})[35,36]$ (fig. 5).

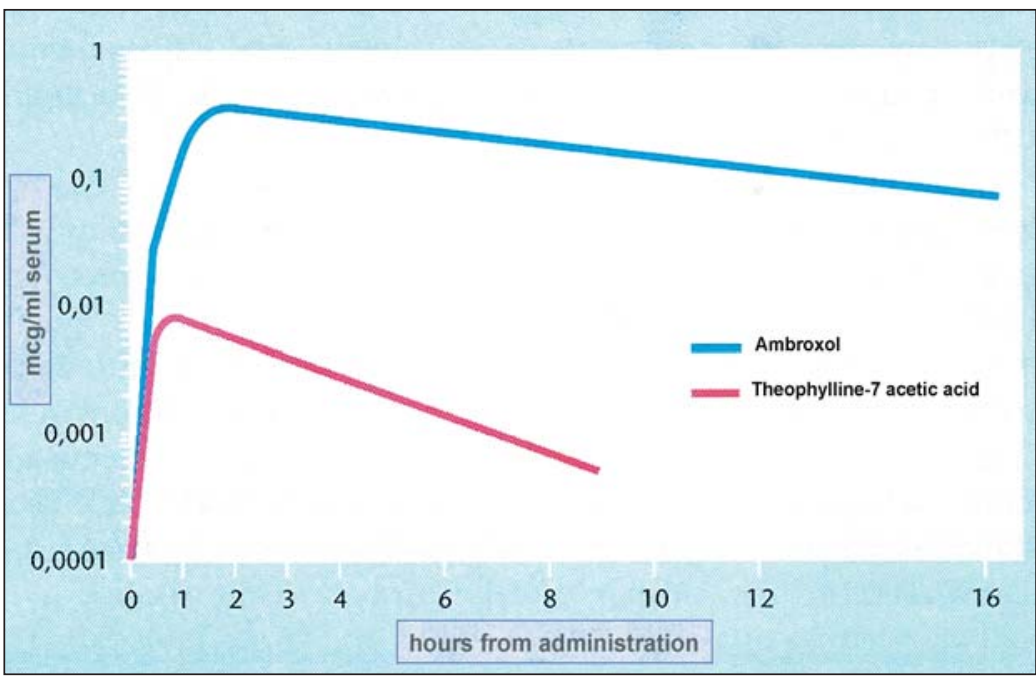

Fig. 5. - Blood levels of the components of acebrophylline in humans.
Another factor in the excellent tolerability of acebrophylline is its pulmonary tropism [37]. The low plasma levels of the xanthine derivative are a further guarantee that there should be no interference with any other theophylline-based drug that might be used concomitantly.

Its stability in an acid environment, excellent tissue diffusion and fairly long half-life mean that acebrophylline need only be taken twice a day.

\section{Clinical pharmacology}

As mentioned earlier, acebrophylline increases the synthesis and release of alveolar surfactant, resulting in triple action: mucoregulation, stimulation of bronchoalveolar clearance, and antiinflammatory-antireactive effect. In patients with chronic obstructive bronchitis, given the drug for 10-20 days, there was a good reduction in expectorate viscosity compared to baseline (between $53 \%$ and $78 \%$ ) $[38-41,32]$ (table 3 ). Acting on both the production and transport of respiratory secretions, acebrophylline avoids the risk (presented by the "classical" mucolytics which have no activity on surfactant production and ciliary beats) of mucus accumulating even if it is fluid [38, 39].

On the basis of the complex relations between bronchial inflammation and hyperresponsiveness and surfactant production, Cocco et al. [24] performed a double-blind trial against placebo to assess the efficacy of acebrophylline, given for 30 days, in reducing aspecific bronchial hyperresponsiveness $(\mathrm{ABH})$ in patients with clinically stable bronchial asthma. There was a mean increase of $86 \%$ in the $\mathrm{PD}_{20}$ $\mathrm{FEV}_{1}$ to metacholine challenge, compared to $32 \%$ in the control arm. These findings gain significance as the only drugs that had achieved a similar effect in the past

Table 3. - Effect of acebrophylline (ACFA) on the rheology of bronchial secretions in humans

\begin{tabular}{|c|c|c|c|c|c|}
\hline Authors (method) & ACFA treatment & Units & $\begin{array}{c}\text { Before } \\
(\text { mean } \pm \text { SD })\end{array}$ & $\begin{array}{c}\text { After } \\
(\text { mean } \pm \text { SD })\end{array}$ & $\Delta \%$ \\
\hline $\begin{array}{l}\text { Barthelemy [38] } \\
\text { (bead viscosimeter) }\end{array}$ & syrup/cap-sules (200 mg/day x 20 days) & $\mathrm{cm} / \mathrm{sec}$ & $44.0 \pm 13.55$ & $153 \pm 7.32$ & -55 \\
\hline $\begin{array}{l}\text { Primbs [39] } \\
\text { (bead viscosimeter) }\end{array}$ & capsules (200 mg/ day x 10 days) & $\mathrm{cm} / \mathrm{sec}$ & 38.0 & 8.2 & -78 \\
\hline $\begin{array}{l}\text { Weber [40] } \\
\text { (bead viscosimeter) }\end{array}$ & capsules (200 mg/ day x 20 days) & cPs & 410 & 152 & -53 \\
\hline $\begin{array}{l}\text { Agliati [41] } \\
\text { (thread length) }\end{array}$ & sachets $(200 \mathrm{mg} /$ day x 14 days & $\mathrm{mm}$ & $25.6 \pm 12.51$ & $35.1 \pm 8.59$ & +37.1 \\
\hline $\begin{array}{l}\text { Allegra [42] } \\
\text { (adhesiveness) }\end{array}$ & syrup (200 mg/day x 10 days) & $\mathrm{dyn} / \mathrm{cm}$ & $75.7 \pm 8.1$ & $51.3 \pm 3.5$ & -32.2 \\
\hline
\end{tabular}


were $\beta_{2}$-agonists. A clinically significant reduction of $\mathrm{ABH}$ was recorded in seven out of ten patients after a single drug dose, and was still detectable $24 \mathrm{~h}$ after the last dose at the end of the month's treatment (fig. 6).

The fact that acebrophylline already changes $\mathrm{ABH}$ after acute administration, and influences its underlying mechanisms after longer treatment, together with its mucoregulating action, suggest it may prove useful in the treatment of asthma-like bronchitis.

Negative interference has been reported between theophylline and erythromycin and in animals simultaneous administration of theophylline together with erythromycin estolate at doses that alone are non-toxic enhanced the toxicity of the former, as indicated by the drastic drop in the LD50, i.e. the dose causing the death of half the animals [18]. In similar experimental conditions, acebrophylline was not affected by simultaneous use of erythromycin, and not only was there no reduction in the LD50 but in some cases it was actu-

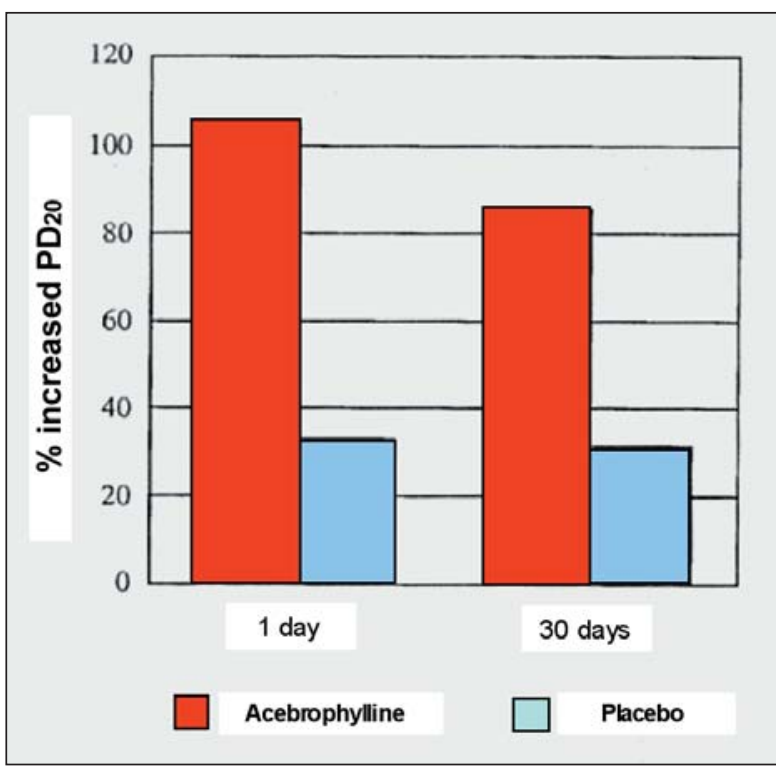

Fig. 6. - Effects of acebrophylline on the state of ABH in asthmatic bronchitic patients.

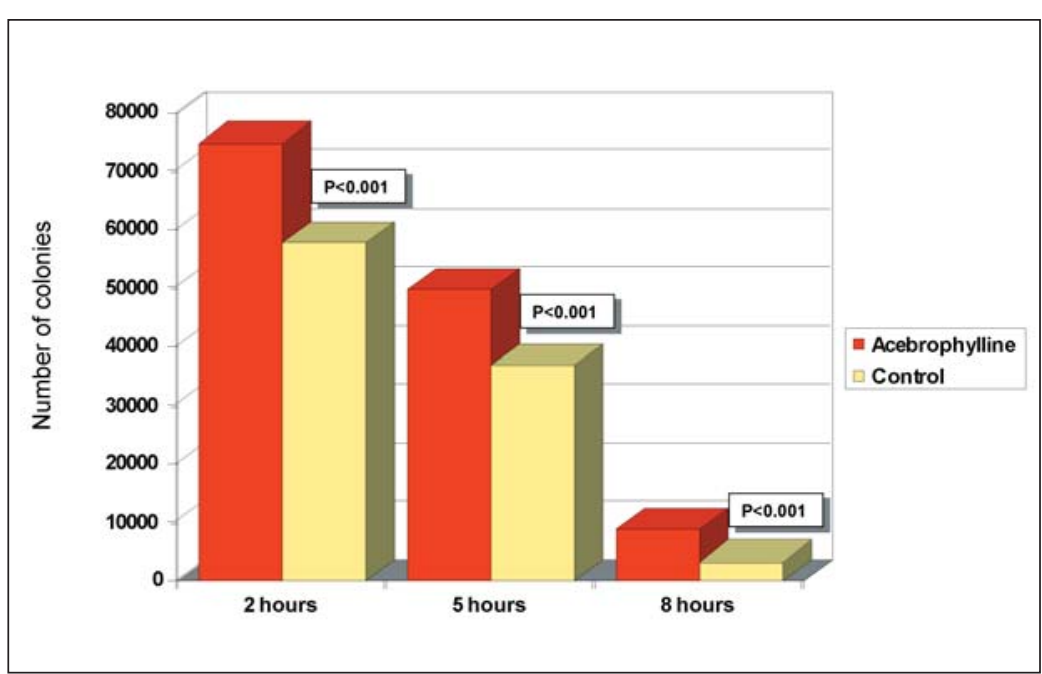

Fig. 7. - Pulmonary clearance of $K$. pneumoniae induced by acebrophylline. ally higher, indicating the safety of the two components as regards their potential tolerability in patients [42].

Acebrophylline also limits the frequency of relapses of infection in patients with chronic obstructive lung disease (COLD) [43]. This is the result of the synergism of action between ambroxol and theophylline-7 acetic acid on surfactant production, which prevents bacteria adhering to the ciliate epithelium [44] and facilitates bronchoalveolar elimination [42] (fig. 7).

\section{Clinical trials}

Two early clinical trials compared the effectiveness of acebrophylline and ambroxol. Milvio et al. [45], in a double-blinded study, treated 41 patients between 30 and 80 years old, with acute or asthma-like bronchitis or flare-ups of chronic forms, with or without fever, increased bronchial secretion, cough and mucous, mucopurulent or purulent sputum. Patients were randomised to receive acebrophylline or ambroxol (both at $100 \mathrm{mg}$ b.i.d.) for 20 days. At the end of this period there was a significant decrease in the amount of sputum in both groups; viscosity was also greatly reduced especially in the patients given acebrophylline. The two treatments relieved clinical symptoms similarly, but acebrophylline increased $\mathrm{FEV}_{1}$ by about $16 \%$, significantly more than ambroxol.

Fracchia et al. [46] reported similar results from their controlled trial comparing acebrophylline $(100 \mathrm{mg}$ b.i.d.) and ambroxol $(30 \mathrm{mg}$ t.i.d.) in 38 patients with COLD, mean age 64.8 years. The two compounds gave similar improvements in mucous visco-elasticity, making it more fluid and easier to expel; this resulted in an improvement - already evident from the third day of treatment - in subjective and objective symptoms compared to baseline. However, after 14 days of treatment, only the patients assigned to acebrophylline showed a statistically significant increase of $\mathrm{FEV}_{1}$ and $\mathrm{VC}$ and a reduction of airway resistance (Raw) (fig. 8).

Similar findings come from subsequent studies on larger caselists. Catena et al. [43], in a multicentre, randomised, parallelgroups trial, enrolled 122 patients, mean age 54.6 years, with stable asthma-like chronic bronchitis, $\mathrm{FEV}_{1}$ between $50 \%$ and $80 \%$ of the expected value, and a positive broncho-reversibility test. Of these, 60 were treated with ambroxol (one 30-mg sachet t.i.d.), and the other 62 received acebrophylline (one 100-mg sachet b.i.d.) for 45 days. Acebrophylline was more active than ambroxol, in relieving clinical signs and symptoms (amount and appearance of sputum, pathological auscultation and dyspnea) and improving respirato- 


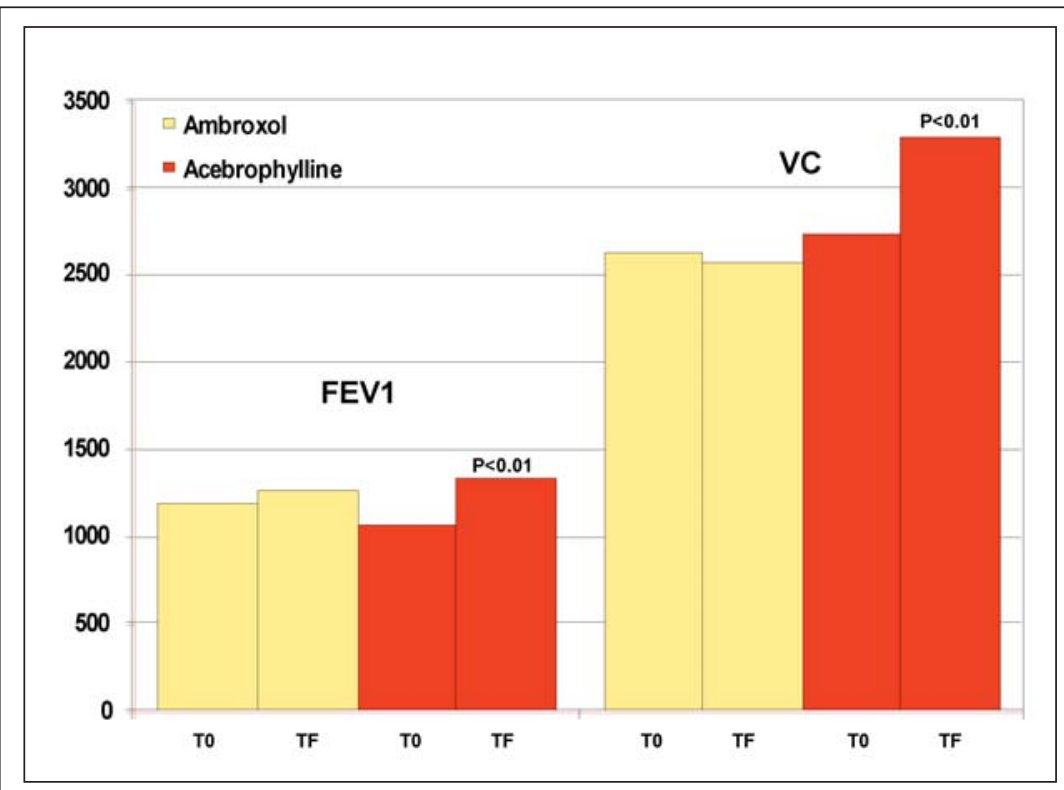

Fig. 8. - Changes in $\mathrm{FEV}_{1}$ and VC induced by acebrophylline and ambroxol in patients with reversible obstruction from airway disease.

ry function $\left(\mathrm{VC}, \mathrm{FEV}_{1}\right.$ and forced expiratory flow, $\mathrm{FEF}_{25-75}$ ) indicative of relief of obstruction; acebrophylline's action was significantly superior to that of ambroxol, as a result of the stronger stimulation of pulmonary surfactant production and more effective mucoregulation. Acebrophylline also significantly reduced the frequency of bronchospastic attacks, the difference reaching significance between 15 and 30 days of treatment; during this period $21 \%$ of patients in the acebrophylline group and $54 \%$ taking ambroxol had at least one episode of bronchoconstriction. The picture improved further between 30 and 45 days of treatment, when the figures were respectively $5 \%$ and $44 \%$. The mean number of bronchospastic episodes was also significantly lower in the acebrophylline patients (tables 4 and 5). Much the same findings were reported from a multicentre, non-controlled trial in 84 patients with asthma-like bronchitis given acebrophylline for 60 consecutive days [47].

In children with asthma-like bronchitis, acebrophylline was compared with ambroxol or a virtual placebo (multivitamin preparation), and the findings were similar to those in adults with the same illness. Fiocchi et al. [48] investigated 30 children with asthma-like bronchitis, aged 2-4 years; one group (16 patients) was given acebrophylline, $5 \mathrm{~mL} /$ day $(50 \mathrm{mg})$, divided in two doses/day, and the other 14 patients were given $9 \mathrm{~mL}$ /day ambroxol $(27 \mathrm{mg})$, in three doses /day. The children were treated for 21 days, followed by two weeks' follow-up. Patients given acebrophylline experienced more prompt and more marked protection against bronchospasm than those given the ambroxol group. This was already evident from the first week, and was particularly striking in the last week of treatment (14-21 days), when none of the 16 children given acebrophylline suffered bronchospasm, compared to six in the ambroxol group (fig. 9). This improvement was reflected in the reduced need for $\beta_{2}$-agonists which was more marked in the acebrophylline group (table 6). Relief of symptoms, particularly those linked to the bronchospasm, was also different in the two groups. Acebrophylline acted sooner than ambroxol to improve pathological auscultation findings and relieve cough (fig. 10).

Another trial in 40 children with infectious asthma, treated with acebrophylline or placebo for 21 days, confirmed these findings [42].

Table 4. - Bronchitic/asthmatic patients reporting episodes of bronchospasm during treatment with acebrophylline and ambroxol

\begin{tabular}{lcccc}
\hline Treatment & $\mathbf{T}-\mathbf{1 5}_{\mathbf{1 5}}-\mathbf{T}_{\mathbf{0}}$ & $\mathbf{T}_{\mathbf{0}}-\mathbf{T}_{\mathbf{1 5}}$ & $\mathbf{T}_{\mathbf{1 5}}-\mathbf{T}_{\mathbf{3 0}}$ & $\mathbf{T}_{\mathbf{3 0}}-\mathbf{T}_{\mathbf{4 5}}$ \\
\hline No. of patients & $29 / 60$ & $33 / 57$ & $31 / 57$ & $25 / 57$ \\
Ambroxol \% & $\mathbf{4 8}$ & $\mathbf{5 8}$ & $\mathbf{5 4}$ & $\mathbf{4 4}$ \\
No. of patients & $28 / 61$ & $26 / 59$ & $12 / 58$ & $3 / 57$ \\
Acebrophylline \% & $\mathbf{4 6}$ & $\mathbf{4 4}$ & $\mathbf{2 1 * *}$ & $\mathbf{5} * *$ \\
\hline
\end{tabular}

$(* *) p<0.01$ Acebrophylline $v s$. ambroxol.

Table 5. - Episodes of broncospasm in bronchitic/asthmatic patients treated with acebrophylline and ambroxol. Mean \pm SD

\begin{tabular}{llll}
\hline No. of episodes & $\mathbf{T}-\mathbf{- 1 5}_{\mathbf{1 5}}-\mathbf{T}_{\mathbf{0}}$ & $\mathbf{T}_{\mathbf{0}}-\mathbf{T}_{\mathbf{1 5}}$ & $\mathbf{T}_{\mathbf{3 0}}-\mathbf{T}_{\mathbf{4 5}}$ \\
\hline Ambroxol & $1.86 \pm 2.9$ & $2.12 \pm 4.6$ & $2.09 \pm 5.7$ \\
Acebrophylline & $1.02 \pm 1.5$ & $0.28 \pm 0.6^{*}$ & $0.05 \pm 0.2^{*}$ \\
\hline
\end{tabular}

(*) $p<0.05$ Acebrophylline $v s$. ambroxol. 


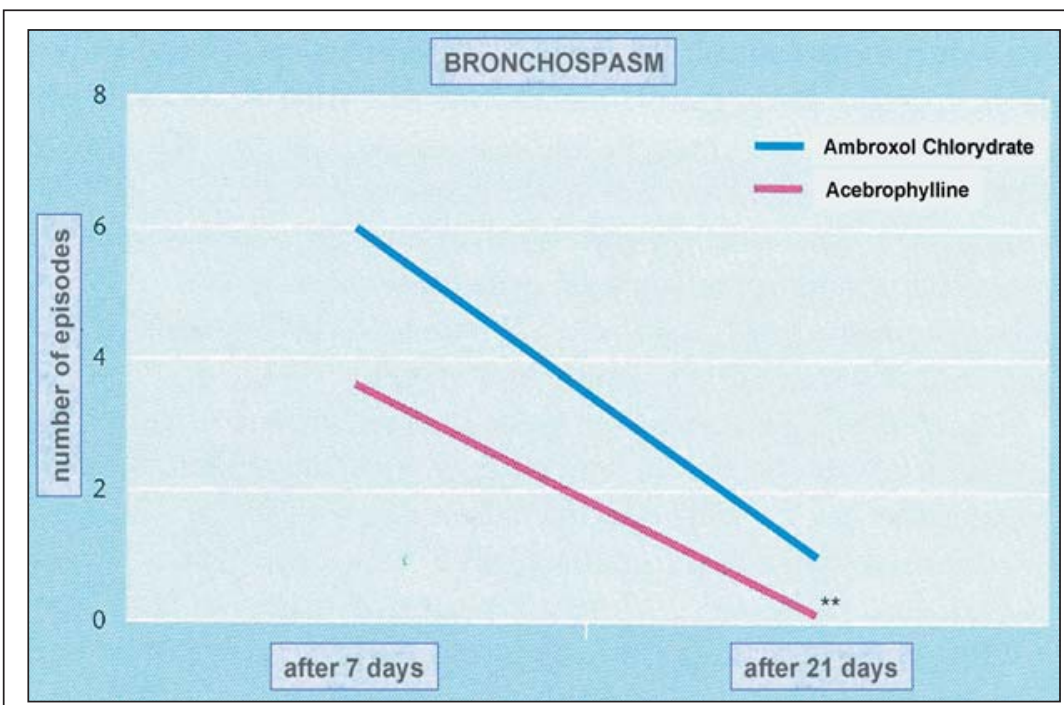

Fig. 9. - Effects of acebrophylline and ambroxol on episodes of bronchoconstriction in children with bronchial asthma. $* *=p<0.01$ vs ambroxol.

Table 6. - Number of doses of $\beta_{2}$-agonists (mean \pm $\mathrm{SD})$ required during treatment with acebrophylline (16 pts) and ambroxol (14 pts)

\begin{tabular}{lcc}
\hline & After 7 days & After 21 days \\
\hline Acebrophylline & $14.4 \pm 1.21$ & 0 \\
Ambroxol & $20.4 \pm 1.74$ & $3.8 \pm 4.91$ \\
\hline
\end{tabular}

\section{Safety in adults and children}

Several trials in adults have confirmed that acebrophylline is well tolerated, with a low rate of adverse reactions, normally only mild gastrointestinal upset $(2.6 \%)$ not requiring any treatment discontinuation, except as a precaution; no abnormalities have been reported in blood chemistry. The drug's safety is further confirmed by the results in children. A post-marketing survey in more than 4000 children with acute bronchitis, either catarrhal, spastic or asthma-like, reported adverse re-

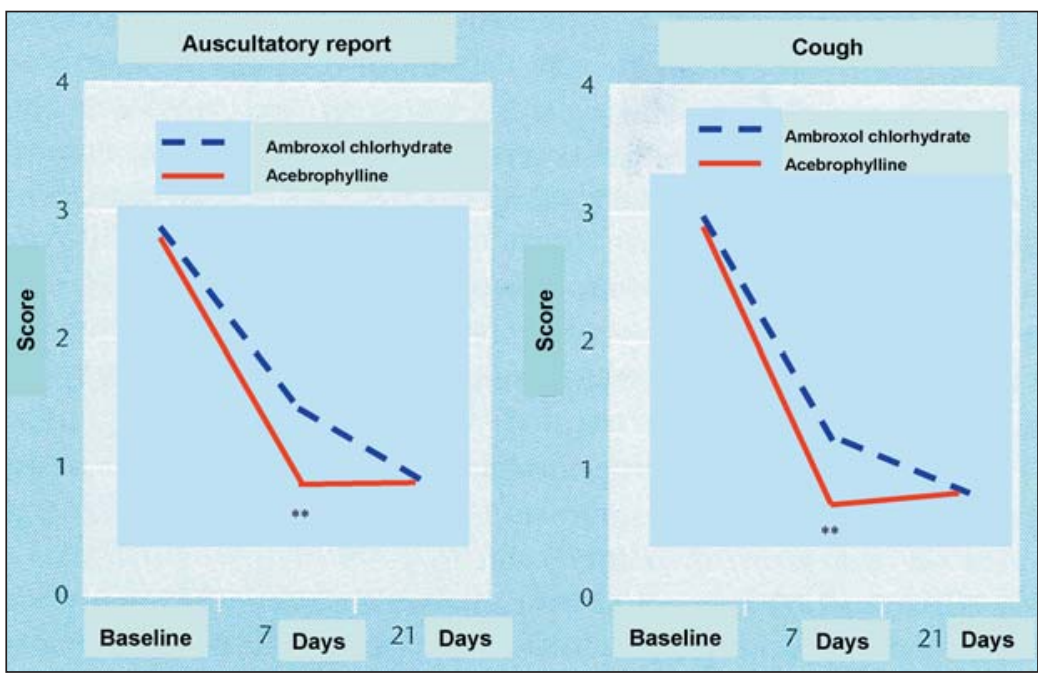

Fig. 10. - Effects of acebrophylline and ambroxol on objective chest findings and cough in children with bronchial asthma. $* *=\mathrm{p}<0.01 \mathrm{vs}$ ambroxol.

(Modified from A Fiocchi, Riv Infett Pediatr 1995; (10): 31-37. actions only in $6.5 \%$. Generally the symptoms were mild and transient, and treatment had to be discontinued only in $0.7 \%$ of cases [49].

\section{Conclusions}

In all the trials comparing acebrophylline and ambroxol in patients with acute or asthma-like bronchitis, relapses of the chronic form [45] or COLD [46], acebrophylline has been more effective than ambroxol, achieving more marked improvement, though not significant, in the visco-elasticity of mucus, making it more fluid, thus easing expectoration. This means that there have been improvements in the subjective and objective symptoms starting by the third day of treatment [46]. However, patients treated with acebrophylline show significant improvements in measures of respiratory function. This might be due to the drug's mechanism of action: its muco-regulating effect and the stimulation of pulmonary surfactant production and release, facilitates the drainage of bronchial secretions, leaving the airways more pervious.

The most important new element in the physiopathology of asthma-like bronchitis is the excessive airway hyper-responsiveness, partly resulting from inflammation, that is a fundamental factor of the disease. From the therapeutic point of view, this means using not only bronchodilators but also drugs that reduce the inflammation, hence also the $\mathrm{ABH}$.

It thus appears that acebrophylline, given orally at the doses indicated for clinical use, reduces the hyper-responsive, inflammatory condition more markedly and more promptly than ambroxol. Among the parameters that showed greatest improvement, the incidence of broncho-spastic episodes is interesting, since they were significantly less frequent in patients receiving acebrophylline. It was also noted that while ambroxol gave relief of mild broncho-constriction, i.e. acting only, on patients with fewer episodes of bronchospasm, acebrophylline also provided a substantial benefit in more severe cases. These findings are in line with the latest international reports indicating that poor-quality, scant surfactant is one pathogenic factor of bronchospasm: therefore, drugs that stimulate surfactant production obviously help preventing this. It has also been suggested that there is a threshold for the optimal surfactant concentration in the airways. Below this threshold the surfactant only has muco-kinetic/muco-regulating activity, whereas above it 
- for instance, after stimulation with acebrophylline - it also has antibronchospastic activity [43].

The numerous trials in adults and children confirm the excellent safety profile of this compound, and the very low rate of adverse reactions.

\section{References}

1. Von Seefeld H, Weiss JM, Rensch H, et al. Neue Konzepte in der therapie dur Mukostase. Prax Klin Pneumol 1983; 37: 896.

2. Rensch H, Von Seefeld H. Surfactant-mucus interaction In: Robertson B, Van Golde L M and Batenburg J J, ed. Pulmonary Surfactant. Elsevier Science Publishers, Amsterdam 1984: 203-214.

3. Bashmakov YK, Bryuscina TS. The phospholipids of pulmonary surfactant as metabolic predecessor of SRSA. (abstr) In abstracts of the Congress of the European Academy of Allergology and Clinical Immunology. Berlin (West), September 1989: 17-22.

4. Scaglione F, De Martini G, Gattei G, et al. Studi sul meccanismo d'azione di acebrofillina: effetto regolatore sulla produzione di leucotrieni. Giorn It Mal Tor 1992; 1 (s): 73-78.

5. Heath MF, Jacobson W. The inhibition of lysosomal phospholipase A from rabbit lung by ambroxol and its consequences for pulmonary surfactant. Lung 1985; 163: 337-344.

6. Fabbri LM. Airway inflammation and asthma: importance of arachidonate metabolites for airway hyperresponsiveness. Prog Biochem Pharmacol 1985; 20: 18-25.

7. Enhorning G. Asthma, a condition of surfactant deficiency. In: L. Ekelund L, B. Jonson B, L. Malm L, ed. Surfactant and the respiratory tract. Elsevier Science Publishers, Amsterdam, 1989: 273-81.

8. Marzetti G, Colarizi P, Agostino R, et al. Pulmonary sequelae in RDS survivors. In: Vignali M, Cosmi EV. ed. Diagnosis and treatment of fetal lung immaturity. 1985: 204-209.

9. Abood G. Enhancement of stereospecific opiate binding to neural membranes by phosphatidyl-serine. Eur $J$ Pharmacol 1976; 39 (1): 71.

10. Seeger W, Stohr G, Wolf H R S, et al. Alteration of surfactant function due to protein leakage: special interaction with fibrin monomer. J Appl Physiol 1985; 58: 326-38.

11. Ekelund L, Andersson K E, Enhorning G. Release of fetal lung surfactant: effects of xanthines and adenosine. In: Andersson KE, Persson CGA, ed. Anti-asthmatic xanthines and adenosine. Amsterdam: Excerpta Medica, 1985: 202-208.

12. Rudnik J, Hanicka M, Pawelek J, et al. Pulmonary surfactant contents in bronchial secretion in children with chronic respiratory diseases estimated by physico-chemical methods. Z Erkrank Atm Org 1983; 160: 44-47.

13. Kurashima K., Ogawa H, Ohka T. A pilot study of surfactant inhalation for the treatment of asthmatic attack. Jpn J Allergol 1991; 40 (2): 160.

14. Collaborative group on antenatal steroid therapy: effect of antenatal dexamethasone administration on the prevention of respiratory distress syndrome. Am J Obstet Gynecol 1981; 141: 276-86.

15. Padbury J F, Hobel C J, Lam R W, et al. Sex differences in lung and adrenal neurosympathetic developments in rabbits. Am J Obstet Gynecol 1981; 141: 199.

16. Cosmi E V. Role of beta-sympathomimetics and aminophylline on fetal lung maturation. In: Vignali M, Cosmi EV, Luerti M, ed. International Workshop "Diagnosis and treatment of fetal lung immaturity" 1986: 128-133. Masson Editore.
17. Nobili A, Garattini S. Interazioni tra farmaci. I corticosteroidi. Aggiornamento Medico 2005; 29: 99.

18. Nobili A, Garattini S. Il paziente asmatico. Interazioni tra farmaci. Aggiornamento Medico 2006; 36: 266-73.

19. Gluck L. Administration of corticoids to induce maturation of fetal lung. Am J Dis Child 1976; 130: 1976.

20. Zavattini G, Leproux G B, Daniotti S. Ambroxol In: Braga P C, Allegra L, ed. Drugs in Bronchial Mucology, Raven Press, 1989: 263-293.

21. Coppi G, Silingardi S. Livelli plasmatici, parametri farmacocinetici e livelli polmonari di ambroxol nel ratto dopo somministrazione endovenosa ed orale di acebrofillina e di ambroxol. Giorn It Mal Tor 1992; 1 (s): 91-96.

22. Scaglione F, Dugnani S, Maccarinelli G, et al. Effetto di acebrofillina sul contenuto e sulla composizione dei lipidi costituenti il surfattante polmonare. Giorn It Mal Tor 1992; (s): 67-72.

23. Genghini M, Bertoletti R, Curti P C. Attività in vitro di acebrofillina su cellule di lavaggio broncoalveolare (BAL). Giorn It Mal Tor 1992; 1 (s): 79-84.

24. Cocco G, Zavattini G., Padovano A, et al. Acebrofillina: studio della morfologia della curva nel broncospasmo da metacolina. Giorn It Mal Tor 1992; 1 (s): 103106.

25. Post M, Batenburg J J, Schunrmans E A, et al. The perfused rat lung as a model for studies on the formation of surfactant and the effect of ambroxol on this process. Lung 1983; 161: 349-59.

26. Prevost M C, Soula G, Douste- Blazy L. Biochemical modifications of pulmonary surfactant after bromhexine derivative injection. Respiration 1979; 37: 215-19.

27. Bracco M, Curti PC. Beschreibung einer histochemischen, fur die oberflachenaktive substanz der alveolen spezifische methode. Arzneim - Forsch 1974; 24: 845-47.

28. Noack W, Elbrecht B. Elektronenmikroskopische untersuchungen uber die wirkung des metaboliten VIII von bisolvon auf die totale rattenlunge (tag 18 und 20 a. p.). Wien Med Wochenschr 1975; 125 (s 23): 26-33.

29. Allegra L, Bossi R, Braga PC. Rheology of bronchial fluids assessed by forced oscillations. In: Cosmi E, Scarpelli E, ed. Pulmonary Surfactant System. Elsevier, Rome, 1983: 319-37.

30. Shimura S, Okubo T, Maeda S, et al. Effect of expectorants on relaxation behaviour of sputum viscoelasticity in vivo. Biorheology 1983; 20: 677-83.

31. Lhermitte M, Lamblin G, Degand P, et al. Affinity of bronchial secretion glycoproteins and cells of human bronchial mucosa for ricinus comunis lectins. Biochimic 1977; 59: 611-20

32. Allegra L. Surfattante: patologia secretoria e acebrofillina. Gior It Mal Tor 1992; 1 (s): 42-44.

33. Bianchi M, Mantovani A, Erroi A et al. Ambroxol inhibits interleukin 1 and tumor necrosis factor production in human mononuclear cells. Agent and Actions 1990; 31: 275-9

34. Chitano P, Di Stefano A, Finotto S, et al. Ambroxol inhibits airway hyperresponsiveness induced by ozone in dogs. Respiration 1989; 55 (s1): 74-78.

35. D'Angelo L. Livelli plasmatici e parametri farmacocinetici di ambroxol ed acido 7-teofillin-acetico dopo somministrazione singola e ripetuta di acebrofillina in soggetti adulti. Giorn It Mal Tor 1992; 1 (s): 85-90.

36. Sved S, McGilveray IJ, Beaudoin N. The assay and absorption kinetics of oral theophylline-7 acetic acid in the human. Biopharm Drug Disposit 1981; 2: 177-84.

37. Mezzetti M, Colombo L. A pharmacokinetic study on pulmonary tropism of ambroxol in patients under thoracic surgery. J Emerg Surg Int Care 1990; 13 (3): 179-85.

38. Barthelemy F. Le theophillinacetate d'ambroxol dans l'hipersecretion bronchique. Acta Ther 1985; 11: 453-57. 
39. Primbs K. Therapeutic activity of ambroxol theophillinacetate in chronic obstructive pulmonary diseases. Clin Ther 1985; 7-6: 733-736.

40. Weber H . Treatment of bronchial asthma. Clinical Trials $J$ 1985; 22 (5): 435-40.

41. Agliati G. Acebrophylline in the treatment of chronic obstructive pulmonary disease. Curr Ther Res 1995; 56 (2): $169-74$

42. Allegra L. Surfattante: trasporto mucociliare e clearance da surfactant: ruolo della cebrofillina. Momento Medico 1992; 69-85.

43. Catena E, Bariffi F, D'Amato G, Iodice F. Efficacia clinico-funzionale dell'acebrofillina nel trattamento di pazienti con bronchite cronica asmatiforme. Giorn It Mal Tor 1992; 1 (s): 97-102.

44. Erne AM, Werner RG, Reinfenrath R. Inhibition of bacterial adhesion by an artificial surfactant. FEMS Microbiol Lett 1984; 23: 205-209.
45. Milvio C, Borellini P, Benazzi, et al. Effetti clinici del teofillin-acetato di ambroxol. Giorn Ist Ric Clin Ter 1985; 4: 77-80.

46. Fracchia C, Della Torre M, Zanotti E, et al. Valutazione dell'attività di acebrofillina (P3011): studio controllato verso ambroxol. Rass Pat App Resp 1987; 1: $177-181$.

47. Cerveri I, Bizzarro D, Calcagna G, et al. Valutazione dell'efficacia e della tollerabilità di acebrofillina in pazienti affetti da bronchite cronica asmatiforme. Giorn It Mal Tor 1992; 1 (s): 107-110.

48. Fiocchi A, Galeone M, Banderali G, et al. Acefillinato di ambroxol nel trattamento della bronchite asmatiforme del bambino (studio controllato verso ambroxol). Riv Infett Pediatr 1995; 10: 31-37.

49. Goldrub N, Soares VRZ, Hamoui A, et al. Therapeutic activity and tolerability profile of acebrophylline. $A d$ van Ther 1992; 9: 107-115.

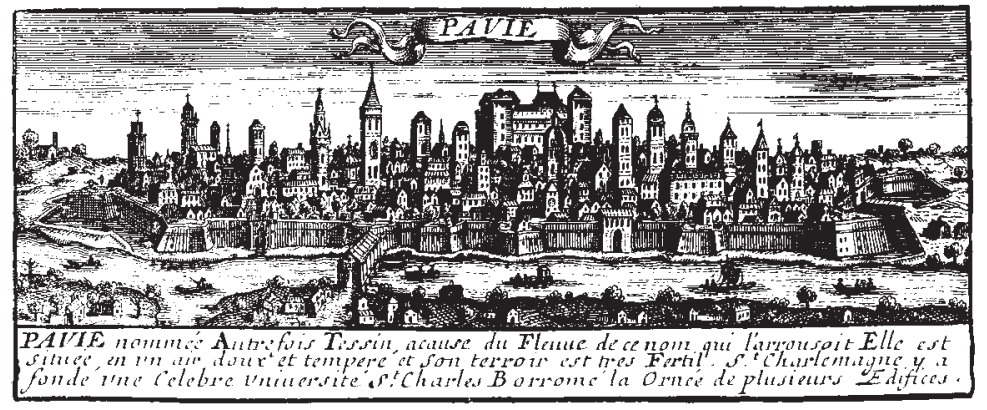

